\title{
Underweight and Factors Associated Among Lactating Mothers In Dodata District, Arsi Zone, Oromia Regional State, Ethiopia,2021
}

Hawa Kedir

Adama Hospital Medical College, Department of Public Health

Godana Arero ( $\sim$ garero2015@gmail.com )

Adama Hospital Medical College, Department of Public Health

\section{Research Article}

Keywords: Underweight, lactating mother, associated factors, Dodota, Ethiopia

Posted Date: August 19th, 2021

DOI: https://doi.org/10.21203/rs.3.rs-770282/v1

License: (c) (i) This work is licensed under a Creative Commons Attribution 4.0 International License.

Read Full License 


\section{Abstract}

Background: An underweight individual is a somebody whose body weight is considered too low (BMI $<18.5$ ) to be healthy. The similar idea applies to lactating mothers. However, little is known about underweight status among lactating women in the study area. The objective of study to assess incidence of underweight and related issues among lactating mothers in Dodota district of Arsi Zone, Oromia, Ethiopia, from February 1-28, 2021.

Method: The cross-sectional study design was done on 355 lactating mothers. The starata and simple random sampling technique were used. The structured questionnaire and anthropometric measurements were used. Data were entered and cleaned using Epi info version 7.1 and SPSS version 21 for analysis. Bivariate and multivariate analysis were done. Descriptive statistics wree performed. The crude and adjusted odds ratio along with $95 \% \mathrm{Cl}$ were used to measure the strength of association. The level of statistical significance was declared at a p-value $<0.05$.

Result: Study revealed (14.1) lactating mother were underweight. Rural areas, (AOR=2.5 [95\% Cl: (1.061, 6.302), the practice of food taboos (AOR=2.3, [95\% Cl: $(1.045,5.084)$ and income level(AOR= $2.1[95 \% \mathrm{Cl}$ : $(1.003,4.460)$ were found to be independent determinants of underweight among lactating mothers in the study area.

Conclusions: The prevalence of underweight among lactating mothers was lower.

\section{Statistical Analysis}

In the first stage, kebeles in the district were stratified into urban and rural-based on administration. Then from the stratum, one urban and four rural representative kebeles selected based on probability using simple random sampling techniques after a list of kebeles as the sampling frame. In the second stage, households with lactating mothers were identified and listed separately in each selected kebele through house-to-house visits by health extension workers.

A sampling frame was prepared by registering all the identified eligible lactating mothers in each selected sub-city. After that, lactating mothers selected proportionally allocated to each kebele based on the size. Finally, a systematic sampling technique was used to select the required number of lactating mothers.

The structured questionnaire was adapted from relevant literature and previous studies and modified based on the study variables and local context $(24,25)$. The English version questionnaire was translated into regional working language (Afan Oromo) by a language expert to make sure that the questions are clear and can be understood by the respondents, and after that, it was translated back to the English version to maintain its consistency. The questionnaires consisted of six basic sections: sociodemographic characteristics, health service-related conditions, feeding practice, dietary diversity, household food security, and anthropometric measurements. 
The dietary patern of the lactating women was collected using sum of consumed food groups within 24 hrs by using 10 food groups. To measure the outcome variable, weight was measured using a portable digital weight scale, and height was measured using a wooden height-measuring board with a sliding head bar(33).

The data were collected by face-to-face interview technique using the adapted questionnaire for lactating mothers.

To measure the weight, women were requested to remove the shoe and wear light close. Data collectors were taken the weight of the study participant on the portable digital scale and the values were recorded to the nearest 100 gram or $0.1 \mathrm{~kg}$. To measure height, women were requested to stand erect with their shoulder level, hands were at the side and their head, scapula, buttock, calve and heel will in contact with a vertical measuring board. The height was measured to the nearest $0.1 \mathrm{~cm}$ using a wooden heightmeasuring board with a sliding head bar following standard anthropometric techniques(4).

Body mass index of the women was calculated through weight in kilogram divided by square of height in meters and based on the result women were categorized into underweight with BMI less than $18.5 \mathrm{~kg} / \mathrm{m} 2$, normal those having BMI $18.5-24.99 \mathrm{~kg} / \mathrm{m} 2$, overweight with BMI $25-29.99 \mathrm{~kg} / \mathrm{m} 2$ and obese those having BMI greater than or equal to $30 \mathrm{~kg} / \mathrm{m} 2$ (2).

\subsubsection{DATA COLLECTION PROCESS}

A total of five health workers were involved in the data collection process. Two BSC Nurses from the health center were supervised and coordinated data collectors. Two days of intensive training were given regarding the objective of the study, procedures of anthropometric measurement, data collection tools, and interview methods by the principal investigator. The principal investigator and supervisors were following the activities every day to make sure the completeness of the questionnaires. The principal investigator was responsible for the overall data collection processes.

\subsection{DATA QUALITY CONTROL}

To assure the quality of the data, semi-structured and pre-tested questionnaires were used. Pretest of the questionnaire was employed beforethe actual data collection period to know the length, content, question-wording, and language understandability of the question among 5\% (i.e., 18 Lactating Women) of the study sample on one kebele not included in this study. The data collectors and supervisors took two days of training by the principal investigator on the instruments, method of data collection, how to take anthropometric measurements, and ethical issues. The Standard Operating Procedure adopted from the WHO anthropometric measurement manual was used on how to measure correct height and weight (34). The weight scale was calibrated using known weight $(\mathrm{Kg})$ and the height scale was calibrated using meter tape. Data collectors checked and assured the functionality of digital weight scales using known 
weight every morning before data collection begins. It was checked using known weight and assuring it read exactly at zero. A respondent's weight and height were measured at least twice and more times when the difference between the two weight measures is greater than $0.1 \mathrm{~kg}$ and when the difference between the height measures is greater than $0.1 \mathrm{~cm}$.

Daily the questionnaires were checked to ensure that whether they are correctly filled or not. Data entry for the questionnaire was performed to realize consistency in data entry and to correct mismatches by crosschecking. In addition, the quality of data collection was ensured through close supervision of the data collectors by the principal investigator.

After completion of data collection and processing, data were checked for completeness, clarity, and consistency. Then data were entered Epi data version 7 and SPSS version 21 for analysis. Binary logistic regression analysis was done to see the association between a dependent variable and each independent variable.

Since the interest was identifying lactating mothers at risk of underweight, the dependent variables were coded as 1 if lactating mother underweight $\left(B M I<18.5 \mathrm{~kg} / \mathrm{m}^{2}\right)$ and coded as 0 if not. Multi Col-linearity effect checked and variables with $\mathrm{SE}>2$ removed from the analysis and those variables that had no collinear effect were included in a binary logistic regression model to see the possible relationships with the outcome variables. Covariates with a p-value less than 0.25 in the bi-variable logistic regression analysis were a candidate for a multivariable logistic regression analysis for potential confounders and to identify risk factors associated with underweight. Odds Ratio along with $95 \%$ Confidence interval measures the strength of the association. Level of statistical significance declared at p-value less 0.05 . The fitness of the model was tested by the Hosmer-Lemeshow goodness of fit test. Finally, results were presented using frequencies, summary measures, tables, and figures.

\section{Results}

A total of 355 respondents enrolled in the study with a response rate of $100 \%$. The mean age and standard deviation of the respondents were $(28.55 \pm 6.53$ ) years (age ranged from 16 to 49 years). Out of the total respondents, about three-fourth(74.4\%) lived in a rural area, 194 (54.6\%) were Muslim followers, $310(83.3 \%)$ were housewife,most of them (98.0\%) were married.Three-fourth $(75.5 \%)$ of the respondentswere literate (who were able to read and write). The family wealth of lactating mothers was assessed and the result showed that 137 (38.6\%) of them hada low wealth index.Near to $3 / 4^{\text {th }}(74.4 \%)$ of the mother had children less than one years of age.(1).

\section{Table 1}

Socio-demographic characteristics of the lactating mothers in Dodota district, Arsi, Oromia region, Ethiopia, 2021 


\begin{tabular}{|c|c|c|c|}
\hline \multicolumn{2}{|l|}{ Variables $(n=355)$} & Frequency & Percentage (\%) \\
\hline \multirow{4}{*}{ Age in years } & $16-25$ years & 132 & 37.2 \\
\hline & $26-35$ years & 168 & 47.3 \\
\hline & $>=36$ years & 53 & 14.9 \\
\hline & Mean $\pm S D$ & $28.55 \pm 6.53$ & \\
\hline \multirow[t]{2}{*}{ Place of Residence } & Urban & 91 & 25.6 \\
\hline & Rural & 264 & 74.4 \\
\hline \multirow{3}{*}{ Religion } & Orthodox & 137 & 38.6 \\
\hline & Muslim & 194 & 54.6 \\
\hline & Protestant & 24 & 6.8 \\
\hline \multirow{4}{*}{ Marital Status } & Married & 348 & 98.0 \\
\hline & Divorced & 3 & 0.8 \\
\hline & Separated & 3 & 0.8 \\
\hline & Widowed & 1 & 0.3 \\
\hline \multirow{3}{*}{ Education (Mother) } & Unable to read and write & 87 & 24.5 \\
\hline & Primary education & 179 & 50.4 \\
\hline & Secondary and above & 89 & 27 \\
\hline \multirow[t]{2}{*}{ Occupation (Mother) } & House wife & 310 & 83.3 \\
\hline & Merchant & 45 & 12.7 \\
\hline \multirow[t]{2}{*}{ No. of Family members } & $<5$ & 173 & 48.7 \\
\hline & $>=5$ & 182 & 51.3 \\
\hline \multirow[t]{3}{*}{ Wealth Index } & Low & 137 & 38.6 \\
\hline & Medium & 92 & 25.9 \\
\hline & High & 126 & 35.5 \\
\hline \multirow[t]{3}{*}{ Education (father) } & Unable to read and write & 57 & 16.1 \\
\hline & Primary education & 161 & 45.4 \\
\hline & Secondary and above & 137 & 38.6 \\
\hline \multirow[t]{2}{*}{ Occupation (father) } & Farmer & 259 & 73.0 \\
\hline & Merchant & 51 & 14.4 \\
\hline
\end{tabular}




\begin{tabular}{|llll|} 
& Government employee & 31 & 8.7 \\
\cline { 2 - 3 } Age of child & Others & 7 & 2.0 \\
& $<5$ Months & 128 & 36.1 \\
\hline $6-11$ months & 136 & 38.3 \\
\hline$>=12$ months & 91 & 25.6 \\
\hline
\end{tabular}

\section{Dietary patterns}

Most $(92.1 \%)$ of lactating mothers recalled that they consumed all starchy staples such as white potatoes, or any other foods made from roots or tubers, bread, kita, porridge, injera, spaghetti, kolo, rice, biscuits, or any other foods made from maize, millet, wheat, teff, barley, oat, and sorghum one day before the day of data collection. However, only $20(5.6 \%)$ of lactating mothers stated that they consumed any organ meat such as liver, kidney, heart, or other organ meats or blood-based foods, 76 (21.4\%)of them consumed any eggs, andone-third (33.2\%) of them consumed all dairy products such as milk or other milk products, cheese, yogurt one day before the day of data collection. Sixty-three(17.7\%) of the respondents were restricted from specific food during lactation. Fourty-two $(11.8 \%)$ of them were food insecured(Table 2). 
Table 2

Twenty-four (24) hours dietary diversity consumption pattern of lactating mothers in Dodota district, Arsi, Oromia region, Ethiopia, 2021

\begin{tabular}{|c|c|c|c|}
\hline Food groups & Categories & Frequency & Percentage (\%) \\
\hline \multirow[t]{2}{*}{ Starch staples } & Adequate intake & 327 & 92.1 \\
\hline & Low intake & 28 & 7.9 \\
\hline \multirow[t]{2}{*}{ Legumes \& Nuts } & Adequate intake & 235 & 66.2 \\
\hline & Low intake & 120 & 33.8 \\
\hline \multirow[t]{2}{*}{ Dairy } & Adequate intake & 118 & 33.2 \\
\hline & Low intake & 237 & 66.8 \\
\hline \multirow[t]{2}{*}{ Organ Meat } & Adequate intake & 20 & 5.6 \\
\hline & Low intake & 335 & 94.4 \\
\hline \multirow[t]{2}{*}{ Eggs } & Adequate intake & 76 & 21.4 \\
\hline & Low intake & 279 & 78.6 \\
\hline \multirow[t]{2}{*}{ Flesh Foods } & Adequate intake & 76 & 21.4 \\
\hline & Low intake & 279 & 78.6 \\
\hline \multirow[t]{2}{*}{ Vitamin-A rich foods } & Adequate intake & 187 & 52.7 \\
\hline & Low intake & 168 & 47.3 \\
\hline \multirow[t]{2}{*}{ Other fruits and vegetables } & Adequate intake & 149 & 85.4 \\
\hline & Low intake & 206 & 14.6 \\
\hline \multirow[t]{2}{*}{ Other Vitamin-A } & Adequate intake & 303 & 85.4 \\
\hline & Low intake & 52 & 14.6 \\
\hline \multirow[t]{2}{*}{ Food Security } & Food secured & 313 & 88.2 \\
\hline & Food Insecure & 42 & 11.8 \\
\hline \multirow[t]{5}{*}{ Number of meals per day } & 1 & 10 & 2.8 \\
\hline & 2 & 41 & 11.5 \\
\hline & 3 & 234 & 65.9 \\
\hline & 4 & 62 & 17.5 \\
\hline & 5 & 8 & 2.3 \\
\hline Food taboo dusring lactation & Yes & 63 & 17.7 \\
\hline
\end{tabular}




\section{Maternal health service utilization related factors}

Three hundred six (86.2\%) of the study participants reported that they had attended Antenatal Care during their pregnancy of the last childand $101(28.5 \%)$ of them visited four and more times health facility for the ANC service. About one-third(33.0\%) of them had two and fewer years of birth intervals for their last pregnancy while $238(67.0 \%)$ had three and more year's intervals.

Two hundred forty-five (69\%) of them attended Postnatal Care. Regarding place of delivery, 240 (67.6) gave birth at a health institution. Most of the lactating mothers (91.3.0\%) hadfive and fewer pregnancies. Almost half $(51.0 \%)$ of the mothers got their first pregnancy when they were less than 20 years old while only $6.0 \%$ of them got their first pregnancy when they are above 25 years old. Eighty five $(23.9 \%)$ of lactating mothers mentioned that they experienced illness in the past two weeks.Sixty-eight (19.2\%) of them not received nutrition education, while $247(86.1 \%)$ of them got information from health workers(Table 3). 


\begin{tabular}{|c|c|c|c|}
\hline \multicolumn{4}{|c|}{ Table 5.3} \\
\hline Variables $(\mathrm{n}=355)$ & & Frequency & Percentage (\%) \\
\hline \multirow[t]{2}{*}{ ANC visit } & Yes & 306 & 86.2 \\
\hline & No & 49 & 13.8 \\
\hline \multirow[t]{3}{*}{ No. of ANC visit } & 4 times and above & 101 & 28.5 \\
\hline & 3 times & 113 & 31.8 \\
\hline & 2 and less times & 141 & 39.7 \\
\hline \multirow[t]{2}{*}{ Place of Delivery } & Home & 115 & 32.4 \\
\hline & Health Facility & 240 & 67.6 \\
\hline \multirow[t]{2}{*}{ PNC for current child } & Yes & 245 & 69.0 \\
\hline & No & 110 & 31.0 \\
\hline \multirow[t]{2}{*}{ Birth interval (in Year) } & $<=2$ & 117 & 33 \\
\hline & $>=3$ & 238 & 67 \\
\hline \multirow[t]{2}{*}{ IIIness in the past 2 weeks } & Yes & 85 & 23.9 \\
\hline & No & 270 & 76.1 \\
\hline \multirow[t]{2}{*}{ No. of Pregnancy } & $1-5$ & 324 & 91.3 \\
\hline & $>=6$ & 31 & 8.7 \\
\hline \multirow[t]{3}{*}{ Age at first pregnancy (years) } & $15-19$ & 181 & 51.0 \\
\hline & $20-24$ & 153 & 43.0 \\
\hline & $>=25$ & 21 & 6.0 \\
\hline \multirow[t]{2}{*}{ Nutrition Education } & Yes & 287 & 80.8 \\
\hline & No & 68 & 19.2 \\
\hline \multirow[t]{3}{*}{ Nutrition information source } & Health workers & 247 & 86.1 \\
\hline & Media & 28 & 9.8 \\
\hline & others & 12 & 4.1 \\
\hline
\end{tabular}

\subsection{Hygiene and sanitation related factors}


Regarding the availability of latrines, 28 (7.9\%) had no access toa toilet facility. Twenty-two $(6.2 \%)$ of them not used to wash their hands after toilet use. Similarly, $15(4.2 \%)$ of lactating mothers not wash their hands before preparing food and before eating. Eighty-three $(23.4 \%)$ of the lactating mothers not use potable water for drinking and about $240(67.6 \%)$ respondents were disposing of household waste in the open field (Figure 5.1).

\subsection{Prevalence of Underweight among Lactating Mothers}

The prevalence of underweight was $14.1 \%(95 \% \mathrm{Cl}: 10.7,18.0)$. The mean weight, height, and BMI were $54.82 \pm 7.70,1.61 \pm 6.87$, and $21.09 \pm 2.62$ respectively(Table 5.4).

\section{Table 5.4}

Anthropometric measurement of lactating mothers in Dodota district, Arsi, Oromia region, Ethiopia, 2021

\begin{tabular}{llll}
$B M I, \mathrm{~kg} / \mathrm{m}^{2}$ & Classification of BMI & Frequency & Percentage (\%) \\
\hline$<18.5$ & Underweight & 50 & 14.1 \\
\hline$>=18.5$ & Not Underweight & 305 & 85.9 \\
\hline Parameter & Mean $( \pm S \mathrm{~S})$ & & \\
\hline Weight $(\mathrm{kg})$ & $54.82 \pm 7.70$ & & \\
\hline Height $(\mathrm{m})$ & $1.61 \pm 6.87$ & & \\
\hline BMI (Body Mass Index $)\left(\mathrm{kg} / \mathrm{m}^{2}\right)$ & & &
\end{tabular}

\section{Factors associated with lactating mother's nutritional status}

The binary logistic analyses revealed that age of the mothers, total number of pregnancies, age at first pregnancy, the residence of the mothers, the birth interval between current and previous child, wealth index, dietary pattern had a P-Value of $<0.25$. After tested for the effects of multicollinearity, model fitnesstest andadjusted for the confounders; residence, food taboos, and wealth indexes of the mothers persisted as significant determinants of underweight among lactating mothers in the study area. Hence, mothers who live in the rural areas had higher $(\mathrm{AOR}=2.5$ [95\% Cl: $(1.06,6.30)$ odds of being underweight as compared to those who live in the urban. Besides, the odds of being underweight was higher for mothers who practice food taboos $(\mathrm{AOR}=2.3,[95 \% \mathrm{Cl}$ : $(1.05,5.08)$ compared to their counterparts. On the other hand, mothers who were in the lower wealth index category were more than 2 times (AOR= $2.1[95 \%$ $\mathrm{Cl}:(1.00,4.46)$ to be underweight compared to those mothers who were in the highest wealth index (Table5). 
Factors associated with nu-tritional status on bivariate logistic regression analysis among lactating mothers in Dodota district, Arsi, Oromia region, Ethiopia, 2021 


\begin{tabular}{|c|c|c|c|c|}
\hline \multirow[t]{3}{*}{ Variables } & \multicolumn{2}{|c|}{ Nutritional Status } & \multirow[t]{3}{*}{ COR(95\% Cl for $\exp (\mathrm{B})$} & \multirow[t]{3}{*}{$\operatorname{AOR}(95 \%$ C.I. for $\operatorname{EXP}(B)$} \\
\hline & Underweight & Normal & & \\
\hline & $\mathrm{n}(\%)$ & $\mathrm{n}(\%)$ & & \\
\hline \multicolumn{5}{|l|}{ Residence } \\
\hline Urban & $7(14.0)$ & $84(27.5)$ & 1 & 1 \\
\hline Rural & $43(86.0)$ & 221(72.5) & $2.3(1.011,5.394)$ & $2.5(1.061,6.302) \star$ \\
\hline \multicolumn{5}{|c|}{ Birth interval } \\
\hline$<2$ years & $10(20.0)$ & 107(35.1) & 1 & 1 \\
\hline$>=2$ Years & $40(80.0)$ & 198(64.9) & $2.1(1.040,4.493)$ & $1.7(.818,3.728)$ \\
\hline \multicolumn{5}{|c|}{ Food taboos } \\
\hline Yes & $14(28.0)$ & $49(16.1)$ & $2.0(1.020,4.046)$ & $2.3(1.045,5.084)^{\star}$ \\
\hline No & $36(72.0)$ & 256(83.9) & 1 & 1 \\
\hline \multicolumn{5}{|c|}{ Wealth index } \\
\hline Lower & $27(54.0)$ & $110(36.1)$ & $2.1(1.047,4.348)$ & $2.1(1.003,4.460)^{\star}$ \\
\hline Medium & $10(20.0)$ & $82(26.9)$ & $1.0(.443,2.535)$ & $1.06(0.421,2.676)$ \\
\hline Higher & $13(26.0)$ & 113(37.0) & 1 & 1 \\
\hline \multicolumn{5}{|c|}{ Dietary diversity } \\
\hline Inadequate & $16(32.0)$ & $68(22.3)$ & $1.6(.854,3.150)$ & $1.5(.808,3.132)$ \\
\hline Adequate & $34(68.0)($ & 237(77.7) & 1 & 1 \\
\hline \multicolumn{5}{|c|}{ History of ANC } \\
\hline No & $9(18.0)$ & $40(13.1)$ & $0.6(.311,1.522)$ & $0.7(.270,1.869)$ \\
\hline Yes & $41(82.0)$ & 265(86.9) & 1 & 1 \\
\hline \multicolumn{5}{|l|}{ PNC } \\
\hline No & 16(32.0) & $94(30.8)$ & $0.9(.498,1.799)$ & $1.1(.535,2.471)$ \\
\hline Yes & $34(68.0)$ & 211(69.2) & 1 & 1 \\
\hline \multicolumn{5}{|c|}{ Experience illness } \\
\hline Yes & $11(22.0)$ & $74(24.3)$ & $0.8(.429,1.806)$ & $0.6(.292,1.657)$ \\
\hline No & $39(78.0)$ & 231(75.7) & 1 & 1 \\
\hline
\end{tabular}




\section{Discussions}

In this study, $14.1 \%$ of lactating motherswere underweight. The study finding is lower than the study conducted in Ambo (21.5\%)(21) and the prevalence of underweight among lactating mothers in Nekemte(20\%)(22), and Southern Ethiopia(17.4\%)(26). But it was comparatively closer to the study conductedin Addis Ababa, (12.7\%)(36). On the other hand, it was much lower than the study findingsfrom Jimma zone, (40.6\%)(37), the mini-review prevalence of underweight among lactating mothers in Northern Ethiopia(50.6\%).However, it was comparatively higher compared to the study conducted in Uganda, (8.2\%)(43). The difference might be because of the differences in the study settings, interventions on maternal nutrition, health and care practices by governmental and nongovernmental organizations in the study area.

In this study, Rural residence of the participants was significantly associated with maternal underweight of which mothers residing in rural areas had higher odds of being underweight compared to those who live in urban areas. The finding is similar toa study that identified positive associations between rural residential areas and increased risk of underweight among lactating mothers living in the Moyale district of Borana Zone(18). The reason could be mothers living in rural areas may be exposed to labor-intensive jobs that increase their energy expenditures. Labor-intensive work was identified as a significant determinant of underweight among lactating mothers in Uganda(43).

Family wealth index was another significant determinant of underweight among lactating mothers in the study area. The wealth index of the lactating mother was found as the major contributors of mothers' dietary practices in Ethiopiaand while income level which might be related to the wealth index was found to be positively associated with increased risk of being underweight among lactating mothers in Ethiopia(33).

Mothers who practiced food taboos during lactations were more likely to be underweight as compared to those who did not practice abstaining from some kinds of food while lactating their children. The study result conforms to study findings that observed food taboos among a specific segment of populations living in Arsi Zone and dominant among populations living in rural areas(39). Foods taboos can result in inadequate dietary intakes that could result in adverse consequences including maternal underweight(40)

\section{Abbreviations}

ANC AnteNatal Care

BMI Body Mass Index

CSA Central Statistical Agency

DDS Dietary Diversity Score

DHS Demographic and Health Survey 
EDHS Ethiopian Demographic and Health Survey

FAO Food and Agriculture Organization

FMOH Federal Minister of Health, Ethiopia

HEW Health Extension Worker

MCH Maternal and Child Health

NGOs Non-Governmental Organizations

NNP National Nutrition Program

PI Principal Investigator

PNC Post Natal Care

UNICEF United Nation International Children's Emergency Fund

WHO World Health Organization

\section{Limitation Of The Study}

Due to the cross-sectional nature of the study design, it is difficult to establish a causal relationship between under weight and independent variables.

Seasonal variation in food consumption might exist so that results regarding dietary information are only limited to the specific season of the year in which the study were conducted.

Since some question asks about past events, recall bias may occur.

\section{Conclusion}

The prevalence of underweight among lactating mothers was lower compared toEDHS findings. Area of residence, family wealth index, and food taboos during lactations were found to be independent determinants of underweight among lactating mothers in the study area.

\section{Recommendations}

\section{For Government sectors}

- Income-generating activities that targeted mothers in the lowest wealth index should be considered. 


\section{For health care providers}

- Behavioral change communications and nutritional counseling on the food diversity and food taboos should be provided. Special focuses requiredfor mothers living in rural areas and those who are in the low wealth category.

\section{For the participants}

- Lactating mothers should consume a variety of diets that should strengthen their health and that of their children without fear of unrealistic consequences.

\section{For researchers}

- Further study that triangulated with a qualitative study is essential to explore the factors associated with food taboos and other contributors of underweight among lactating mothers.

\section{Declarations}

\section{ACKNOWLEDGMENTS}

My first heartfelt gratitude goes to Adama Hospital Medical College, Department of Public Health for gave me the chance to join the Master of General Public Health program and conducting this research. I would also like to thanks my Advisors Dr. Godana Arero and Mr. Worku Dugasa for their supportive, constructive comments and guidance through my proposal preparation. I would also like to thank Dodota district health office and staffs who supported me during the data collection process.

\section{ETHICAL CONSIDERATIONS:}

Ethical clearance was obtained from the Institutional Health Research Ethics Review Committee (IHRERC) of the college of public health, Adama Hospital Medical College. A written permission letter was obtained from Arsi zonal Health department. For all study participants, information was given about the study before the data collection on its possible risk, benefit, confidentiality, privacy, voluntary activity, right of withdrawal, and the time the questionnaire will take. Then informed, voluntary, written, and oral consent was obtained from each participant. Personal identification was not written on the questionnaire and confidentially of all information was kept. When mothers were found as underweight during data collection, counseling was provided about feeding and then linked to HEWs for SFP.

\section{References}


1. FMOH. ENA Training guide for Health Workers: To Improve the Nutrition of Children and Women. 2014.

2. WHO. Global Database on Body Mass Index. retrieved on May/08/2020, 2012.

3. UNICEF. Infant and Young Child feeding response. 2011.

4. McGuire S, FAO, IFAD, \& WFP. The State of Food Insecurity in the World 2015: Meeting of the 2015 International Hunger Targets: Taking Stock of Uneven Progress. Rome: FAO. Advances in Nutrition, 6(5), 623-624 https://doiorg/103945/an115009936. 2015.

5. Egelbert Bain. Malnutrition in Sub-Saharan Africa: Burden, Causes and Prospects. The Pan African medical journal. 2013;15:120.

6. Federal Democratic Republic of Ethiopia (2015) National Nutrition Program June 2013-June 2015.

7. FMOH. National Nutrition Program II (2016-2020). 2016.

8. Sanusi R. FO. The Nutritional Status of Mothers Practicing Breastfeeding, 8,46-59. 2014.

9. Kiday Haileslassie, Afework Mulugeta, Meron Girma. Feeding Practices, Nutritional Status and Associated Factors of Lactating Women in Samre Woreda, South Eastern Zone of Tigray, Ethiopia. Nutrition Journal 2013;12:28.

10. Save The Children. State of the World's Mothers: Nutrition in the First 1,000 Days. Available at: https://resource centre.save the children.net/library. 2012.

11. Robert Black, Cesar Victora, Susan Walker, Zulfiqar Bhutta, Parul Christian, Mercedes Onis, Majid Ezzati and, et al. Maternal and Child Undernutrition and Overweight in Low-income and Middle Income Countries, Lancet 382(98) pp427-451. 2013.

12. Adhiparasakthi J, Melmaruvathur S, Kancheepuram, Tamilnadu. Nutritional Status among Lactating Women and Predictors of Infant Weight gain in Rural Area of Wardha, India, Journal of Maternal and Child Health,. 2013;15 (3), pp. 1-8.

13. RAO N., Balakrishna N., Arlappa A., and Brahmam G. Diet and Nutritional Status of Women in India,. J Hum Ecol 2017;29(3), pp. 165-170.

14. Khan Yasmeen Majid, Asmat Khan. A Study on Factors Influencing the Nutritional Status of Lactating Women in Jammu, Kashmir and Ladakh regions. Inter J Advancements Res Technol. 2012;1(4):65-74.

15. WHO. Nutrition in the WHO African Region. Brazzaville:Licence: CC BY-NC-SA 3.0 IGO. 2017.

16. Egelbert Bain. Malnutrition in Sub-Saharan Africa: Burden, Causes and Prospects. The Pan African medical journal. 2013;15:120.

17. Mihretu Alemayehu, Alemayehu Argaw, and Abebe Gebremariam. Factors Associated with Malnutrition among Lactating Women in Subsistence Farming Households from Dedo and SeqaChekorsa Districts, Jimma Zone. Devel Country Studies; 5: 21. 2015.

18. Hailu Bekele, Gebi Husein, and Ashenafi Habtamu: Undernutrition and Associated Factors among Lactating Women: Community-Based Cross-Sectional Study in Moyale District, Borena Zone, 
Southern Ethiopia.Hindawi.Advances in Public Health Volume 2020, Article ID 4367145, 10 pages https://doi.org/10.1155/2020/4367145.

19. Hailu Bekele, Gebi Husein, and Ashenafi Habtamu: Undernutrition and Associated Factors among Lactating Women: Community-Based Cross-Sectional Study in Moyale District, Borena Zone, Southern Ethiopia.Hindawi.Advances in Public Health Volume 2020, Article ID 4367145, 10 pages https://doi.org/10.1155/2020/4367145.

20. Amanuel Eramo. Determinants of Underweight among Lactating Mothers: In Anlemo Woreda, Hadiya Zone, Southern Ethiopia: Addis Ababa University; 2018.

21. Eshetu Zerihun, Gudina Egata, and Firehiwot Mesfin. Under Nutrition and its Associated Factors among Lactating Mothers in Rural Ambo District, West Shewa Zone, Oromia Region, Ethiopia. East African Journal of Health and Biomedical Sciences,. 2016;Volume 1 (1): 39-48.

22. Temesgen Desisa, Habtamu Fekadu, Dessalegn Wirtu, Dunkana Negusa. Nutritional Status and Associated Factors among Lactating Mothers in Nekemte Referral Hospital and Health Centers, Ethiopia. Food Science and Quality Management 2015;www.iiste.org ISSN 2224-6088 (Paper) ISSN 2225 - 0557 (Online)Vol.35.

23. Sileshi Garoma, Biru KM. Factors Associated with Underweight among Lactating Mothers in Adama District, Oromia Region, Ethiopia. J Orthop Bone Res 2018;1: 101.

24. Sileshi Berihun, Getachew Kassa, and Muluken Teshome. Factors associated with Underweight among Lactating Women in Womberma Woreda, Northwest Ethiopia; a Cross-Sectional Study. BMC Nutrition. [journal article]. 2017 May 26;3(1):46.

25. Mihretu Alemayehu, Alemayehu Argaw, and Abebe Gebremariam. Factors Associated with Malnutrition among Lactating Women in Subsistence Farming Households from Dedo and SeqaChekorsa Districts, Jimma Zone. Devel Country Studies; 5: 21. 2015.

26. Hadiya Hassen, Samson Gebremedhin, Addisalem Mesfin, Suzan Whiting. Prevalence and Factors Associated with Undernutrition among Exclusively Breast-feeding Women in Arba-Minch Zuria District, Southern Ethiopia. Ethiop J Health Sci. 2019;2018;29(1):913.doi:http://dx.doi.org/10.4314/ejhs.v29i1.13.

27. Zerihun Tariku, Gudina Egata, Alemayehu T. Undernutrition and its Associated Factors among Lactating Women in Gog District, Angwa Zone, Gambella Region, Southwest Ethiopia. 2018.

28. Melaku Tadege, Alemayehu Digssie, Sofonyas Abebaw, Desalegn Tesfa. Chronic Energy Deficiency and its Associated Factors Among Lactating Women in Debre Tabor General Hospital, Northcentral Ethiopia. Journal of Family Medicine and Health Care 2019;Vol. 5, No. 1, 2019, pp. 1-7. doi: 10.11648/j.jfmhc.2019.0501.11.

29. Beruk Berhanu, Christine Lambert, Simon Riedel, Tegene Negese, Hanas Konrad. Ethiopian Orthodox Fasting and Lactating Mothers: Longitudinal Study on Dietary Pattern and Nutritional Status in Rural Tigray, Ethiopia. International journal of environmental research and public health. 2018;15(8):1767.

30. Moges Muluneh, Alehegn Bishaw. Low Dietary Diversity and Associated Factors among Lactating Mothers in Angecha Districts, Southern Ethiopia. BMC Res Notes 2018;11:892. 
31. Haji Aman Deybasso, Shimeles Ololo Sinkie, Ashenafi Habtamu Regesu.Anemia and Associated Factors among Drought Affected Children Aged 6-59 Months. International Journal of Health Sciences and Research.International Journal of Health Sciences \& Research (.org)181Vol.9; Issue: 1; January 2019International Journal of Health Sciences and Research. www.ijhsr.org ISSN: 22499571.

32. Girum Dagne.Determinants of Food Security in Farm Household in Drought Prone Area of Oromia Region: In Case of Dodota District.Journal of Economics and Sustainable Development. 2016ISSN 2222 - 1700 (Paper) ISSN 2222-2855 (Online) Vol.7, No.17,.

33. FAO and FHI 360. Minimum Dietary Diversity for Women a Guide to Measurement. FAO: Rome, Italy. 2016:82.

34. Lartey A. Maternal and Child Nutrition in Sub-Saharan Africa: Challenges and Interventions. Proceedings of the Nutrition Society. 2013;67(1):105-8.

35. Lemma Getacher, Gudina Egata, Tadesse Alemayehu, Agegnehu Bante3, and Abebaw Molla. Minimum Dietary Diversity and Associated Factors among Lactating Mothers in Ataye 1 District, North Shoa Zone, Central Ethiopia: A Community-based Cross-sectional Study. 2020. https://doi.org/10.1101/2020.10.17.20214320.

36. Tesfay Birhane Gebremariam.Household Food Insecurity and Women's Nutritional Status in Addis Ababa.International Journal of Food Science and Biotechnology 2017; 2(2): 24-30 doi:

10.11648/j.ijfsb.20170202.12.

37. Sirawdink Fikreyesus, Tefera Belachew, Oliver Hensel. Fighting Hidden Hunger: Diversity, Composition and Nutrient Adequacy of Diets of Lactating Mothers in Jimma Zone, Southwest Ethiopia. Tropentag, Vienna, Austria. 2016.

38. Quraish Sserwanja and Joseph Kawuki. Prevalence of Underweight and Associated Factors among Lactating Women in Ethiopia: A Mini-review Journal of Advances in Medicine and Medical Research . June 2020 DOI: 10.9734/JAMMR/2020/v32i830459.

39. Zerfu, Taddese Alemu et al. "Dietary habits, food taboos, and perceptions towards weight gain during pregnancy in Arsi, rural central Ethiopia: a qualitative cross-sectional study." Journal of health, population, and nutrition vol. 35,1 22. 25 Jul. 2016, doi:10.1186/s41043-016-0059-8.

40. Chakrabarti S, Chakrabarti A. Food taboos in pregnancy and early lactation among women living in a rural area of West Bengal. J Family Med Prim Care. 2019;8(1):86-90. doi:10.4103/jfmpc.jfmpc_53_17.

41. Dodota district health office, 2013 EC Polpulation profile

42. Bereket Duko et al. "Factors associated with nutritional status among lactating mothers at Shashemene Woreda, West Arsi Zone, Oromia, Ethiopia: A comparative cross-sectional study' Faculty of Health Sciences, College of Medicine and Health Sciences, Hawassa University, Hawassa, Ethiopia. 2018

\section{Figures}




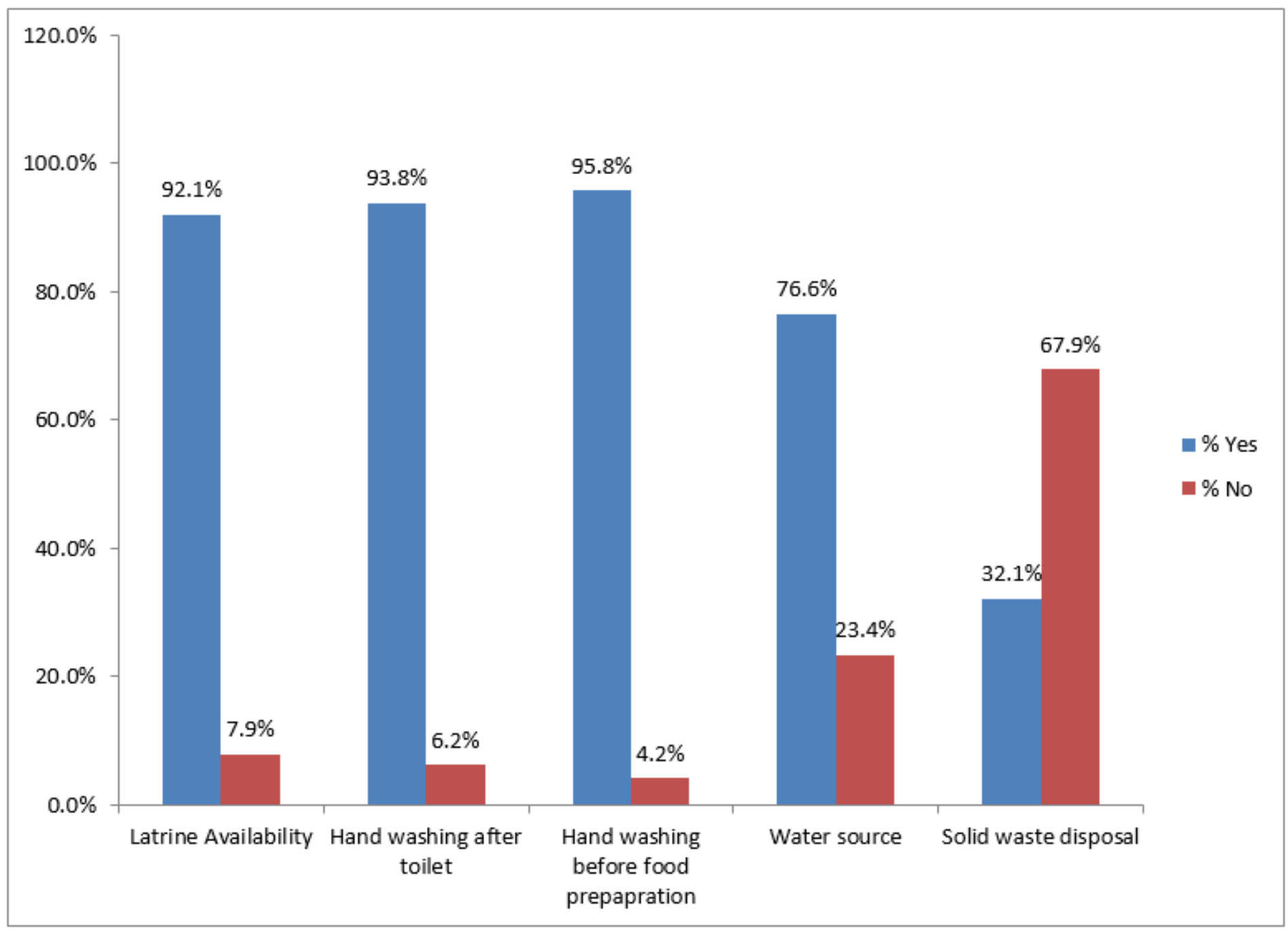

\section{Figure 1}

Hygiene and sanitation conditions of lactating mothers in Dodota district, Arsi, Oromia region, Ethiopia, 2021 